\title{
Dose dependent increased mortality risk in COPD patients treated with oral glucocorticoids
}

\author{
A.M.W.J. Schols*, G. Wesseling*, A.D.M. Kester ${ }^{\#}$, G. de Vries*, R. Mostert ${ }^{\top}$, J. Slangen ${ }^{+}$, \\ E.F.M. Wouters*
}

\begin{abstract}
Dose dependent increased mortality risk in COPD patients treated with oral glucocorticoids. A.M.W.J. Schols, G. Wesseling, A.D.M. Kester, G. de Vries, R. Mostert, J. Slangen, E.F.M. Wouters. C ERS Journals Ltd 2001.

ABSTRACT: Systemic corticosteroids are often administered in COPD patients. The relationship between systemic glucocorticoids and mortality in patients with moderate to severe chronic obstructive pulmonary disease (COPD) was retrospectively analysed. Baseline characteristics of the patients, in stable clinical condition, were collected on admission to a pulmonary rehabilitation centre. Overall mortality was asessed at the end of follow-up. The Cox proportional hazards model was used to quantify the relationship between glucocorticoid use, distinguishing administration route (oral/inhalation) and oral dose, and overall mortality, adjusted for the influence of age, sex, smoking, lung function, resting arterial blood gases and body mass index.

On multivariate analysis, oral glucocorticoid use at a (prednisone equivalent) dose of $10 \mathrm{mg}^{-\mathrm{day}^{-1}}$ without inhaled glucocorticoids, was associated with an increased risk $(\mathrm{RR}=\mathbf{2 . 3 4}, 95 \%$ confidence interval $(\mathrm{CI}) \mathbf{1 . 2 4}-4.44)$ while $15 \mathrm{mg}^{-12 y^{-1}}$ carried a relative risk of 4.03, $\mathrm{CI}=1.99-8.15)$. A significant interaction was observed between inhaled and oral glucocorticoid use. Combined with inhaled glucocorticoids, the relative risk of oral glucocorticoid use appeared to be significantly smaller.

It is concluded that in severe chronic obstructive pulmonary disease, maintenance treatment with oral glucocorticoids is associated with increased mortality in a dosedependent manner. Since the present study design cannot exclude the possibility of bias by indication, further prospective studies are indicated using a broader patient characterization.
\end{abstract}

Eur Respir J 2001; 17: 337-342.

Depts of *Pulmonology and, ${ }^{*}$ Methodology and Statistics and ${ }^{+}$Epidemiology, Maastricht University, Maastricht and 'Asthma Centre Hornerheide, Horn, the Netherlands.

Correspondence: A.M.W.J. Schols, Dept of Pulmonology, University Hospital Maastricht, P.O. Box 5800, 6202 AZ, Maastricht. Fax: 31433875051

Keywords: Chronic obstructive pulmonary disease

corticosteroids

survival

systemic administration

Received: February 162000

Accepted after revision October 242000
The precise role of glucocorticoids in the treatment of chronic obstructive pulmonary disease (COPD) is controversial. A meta-analysis suggests that 20-30\% of COPD patients will benefit from prolonged oral glucocorticoid therapy and typically, $\sim 10 \%$ of COPD patients will experience a $20 \%$ increase in (FEV1) [1]. Possible indications for the use of maintenance treatment with oral glucocorticoids include frequent exacerbations and a rapid decrease in lung function. For both these indications, effectiveness of maintenance treatment has not been conclusively demonstrated [2]. Otherwise, steroid advocates recommend maintenance doses of $7.5-15 \mathrm{mg} \cdot \mathrm{day}^{-1}$ for those patients who do show significant clinical benefit [3], mainly in patients with a certain degree of reversibility of airflow obstruction and with a less severe disease. A retrospective uncontrolled study suggested that a dose of prednisone $>7.5 \mathrm{mg} \cdot \mathrm{day}^{-1}$ is needed to slow down the progression of COPD [4].

Systemic glucocorticoids are frequently prescribed for exacerbations of the disease and have been shown to be effective in improving FEV1 [5], but even when given for exacerbations, the beneficial effects of systemic steroids appear to be limited to the first two weeks only [6].

When prescribing oral glucocorticoids, the treatment efficacy has to be balanced against potential adverse side effects. Side effects of prolonged oral corticosteroid use are well-documented and consist of skin damage, myopathy, diabetes, cataracts and osteoporosis [7]. The older COPD population is especially susceptible to these complications. Potential positive or even negative effects of prolonged inhaled or oral glucocorticoid treatment on survival in COPD have not been adequately evaluated and well-designed prospective studies are not yet available.

The aim of the present study was to evaluate, in a retrospective manner, the association between maintenance treatment with glucocorticoids and overall mortality in moderate to severe COPD patients, adjusted for the influence of age, sex, smoking, lung function, resting arterial blood gases and body mass index. Since adverse systemic effects have been described mainly for high dose oral glucocorticoids, glucocorticoid treatment was categorized by administration route and oral glucocorticoid dose.

\section{Methods}

\section{Patients}

Five-hundred and fifty-six patients with chronic obstructive pulmonary disease who were in a clinically stable condition and who had been admitted to a 
rehabilitation centre (Asthma Centre Hornerheide, Horn, the Netherlands) between 1987 and 1991 to participate in an inpatient pulmonary rehabilitation programme were studied. Patients were eligible for the study if they had COPD according to the American Thoracic Society guidelines, FEV $1<70 \%$ of predicted with an increase in FEV $1<15 \%$ of the pred value after administration of a bronchodilating agonist $(400 \mu \mathrm{g}$ salbutamol). Those with unstable disease or with other confounding disorders such as malignancies, insulindependent diabetes mellitus, and thyroid or cardiovascular disease were excluded. The rehabilitation programme included education and information on smoking cessation, psychosocial support, various modes of physiotherapy and exercise training, nutritional support and instructions on optimal use of medications. Characteristics of the study group are presented in table 1. Mean FEV1 and post-bronchodilator response indicated a group with moderate to severe irreversible airflow obstruction. The majority of patients were current or exsmokers.

\section{Measurements}

FEV1 and inspiratory vital capacity (IVC) were measured with a wet spirometer; the highest value of at least three acceptable spirometric manoeuvers was used. Prebronchodilator and postbrochodilator FEV1 and IVC were expressed as a percentage of the reference values [8]. Arterial blood gases were drawn by puncture of the brachial artery at rest while the subjects breathed room air. Arterial oxygen tension $\left(\mathrm{Pa}_{\mathrm{a}} \mathrm{O}_{2}\right)$ and arterial carbon dioxide tension $\left(\mathrm{Pa}_{\mathrm{a}} \mathrm{CO}_{2}\right)$ were analysed on a blood gas analyser (ABL 330; Radiometer, Copenhagen, Denmark). Data about static lung volumes and diffusing capacity were not available for all patients and were therefore not included in the statistical analysis. Body height was measured with subjects standing barefoot and determined to the nearest $0.5 \mathrm{~cm}$ (Lameris WM 715; Breukelen). Body weight without clothes was measured on a beam scale (SECA, Germany).

\section{Statistical analysis}

Follow-up data on mortality were obtained at the end of follow-up. In a random sample of patients $(\mathrm{n}=100)$ glucocorticoid use and lung function was monitored twice at the pulmonary rehabilitation centre,

Table 1.-Characteristics of the study population

\begin{tabular}{lc}
\hline Sex F/M & $141 / 415$ \\
Age yr & $65 \pm 8$ \\
Height cm & $168 \pm 8$ \\
Weight kg & $66 \pm 13$ \\
Body mass index $\mathrm{kg} \cdot \mathrm{m}^{-2}$ & $23.2 \pm 4.4$ \\
$\mathrm{FEV} 1 \%$ pred prebronchodilator & $36 \pm 13$ \\
$\mathrm{FEV1} \%$ pred postbronchodilator & $39 \pm 12$ \\
$\mathrm{IVC} \%$ & $73 \pm 18$ \\
$\mathrm{~Pa}, \mathrm{O}_{2} \mathrm{kPa}$ & $8.9 \pm 1.6$ \\
$\mathrm{~Pa}, \mathrm{O}_{2} \mathrm{kPa}$ & $5.4 \pm 0.9$ \\
\hline
\end{tabular}

Data presented as mean \pm SD. F: female; M: male; FEV1: forced expiratory volume in one second; IVC: inspiratory vital capacity; $\mathrm{Pa}, \mathrm{O}_{2}$ : arterial oxygen tension; $\mathrm{Pa}, \mathrm{CO}_{2}$ : arterial carbon dioxide tension. with 2-yr intervals during the follow-up. In all these patients mean oral and inhaled maintenance glucocorticoid medication and dose was the same as during the rehabilitation period. Duration of oral glucocorticoid treatment was $>6$ months in nearly all patients. However, information about the reason for prescription and the exact duration of treatment prior to admission could not be reliably obtained and was therefore not considered in the statistical analyses.

Survival plots for a) oral glucocorticoid use versus no steroids and b) inhaled glucocorticoids versus no steroids, were drawn and analysed using the KaplanMeier method. A log-rank Chi-squared test for comparing the survival between groups was used to analyse the association of glucocorticoid use with survival. Use of oral glucocorticoids was categorized by oral dose $(5,10$, $15 \mathrm{mg}$ ). Oral glucocorticoids were initially studied for fluoridated (betamethasone) and nonfluoridated (prednisolone) types separately, but since no difference was found in the mortality risk between the two types (data not shown), equipotent prednisone doses were calculated and used in further analyses. Mortality was assessed as overall mortality from all causes. A twosided value of $\mathrm{p}<0.05$ was considered significant.

Multivariate analyses of the independent contribution of glucocorticoids (categorized by administration route (oral/inhalation) and oral dose and adjusting for the significant (likelihood ratio test, $\mathrm{p}<0.001$ ) interaction between oral and inhaled glucocorticoid use on mortality, was assessed using the Cox proportional hazards model. Other variables included in the model were FEV1 as \% pred, body mass index (BMI) and resting arterial blood gases $\left(\mathrm{Pa}_{\mathrm{a}} \mathrm{O}_{2}\right.$ and $\left.\mathrm{Pa}, \mathrm{CO}_{2}\right)$ as continuous variables and smoking $(0=$ no/ex, $1=$ smoking) and sex $(0=$ males, $1=$ females $)$ as categorized variables. Crude and adjusted relative risks (RR) with and without adjustment for the interaction between oral and inhaled steroid use are shown in table 2 . The $\mathrm{RR}$ corresponding to a risk factor in this model is the exponential of the regression coefficient. Baseline comparisons between the four treatment groups were performed by unpaired student t-test with Bonferroni correction for multiple comparisons. Data were analysed using the statistical package for the social sciences (SPSS) for Windows statistical package (SPSS Inc., Chicago, IL, USA).

\section{Results}

Table 2 shows the results of the bivariate analyses for baseline variables and corticoid use on survival (crude relative RR). Median survival was 38 (95\% CI: $35-41)$ months. Two-hundred and eighty patients died during follow-up. Male sex, high values for age and $\mathrm{Pa}_{2}, \mathrm{CO}_{2}$, and low values for BMI, FEV1 and $\mathrm{Pa}_{\mathrm{a}} \mathrm{O}_{2}$ were significantly associated with increased mortality. Oral glucocorticoids at doses of $\geqslant 10 \mathrm{mg}$ were associated with increased mortality (RR: 3.296; 95\% CI: $1.757-6.183)$. In contrast glucocorticoids by inhalation were associated with decreased mortality (RR: 0.547; 95\% CI: $0.426-0.703$ )

Eighteen per cent of the patients were on oral glucocorticoids only, while $52 \%$ used both inhaled and oral glucocorticoids. Inhaled glucocorticoids only were used by $22 \%$ while $8 \%$ used no glucocorticoids (table 3 ). 
Table 2. - Multivariate Cox proportional hazard model for survival

\begin{tabular}{|c|c|c|c|c|c|}
\hline Covariate & RR crude & $95 \% \mathrm{CI}$ & $\mathrm{RR}$ adjusted & $95 \% \mathrm{CI}$ & p-value \\
\hline Age yr & 1.040 & $1.025-1.055$ & 1.033 & $1.015-1.051$ & 0.0002 \\
\hline BMI $\mathrm{kg} \cdot \mathrm{m}^{-2}$ & 0.927 & $0.900-0.954$ & 0.945 & $0.913-0.979$ & 0.0016 \\
\hline Smoking $0 / 1^{+}$ & 1.314 & $0.916-1.884$ & 1.007 & $0.669-1.517$ & 0.9726 \\
\hline FEV $1 \%$ & 0.986 & $0.977-0.995$ & 0.994 & $0.982-1.006$ & 0.3046 \\
\hline$P a, \mathrm{O}_{2} \mathrm{kPa}$ & 0.843 & $0.780-0.911$ & 0.925 & $0.838-1.021$ & 0.1228 \\
\hline$P \mathrm{a}, \mathrm{CO}_{2} \mathrm{kPa}$ & 1.187 & $1.050-1.342$ & 1.003 & $0.849-1.187$ & 0.9691 \\
\hline Sex $0 / 1^{\#}$ & 0.700 & $0.529-0.926$ & 0.845 & $0.608-1.173$ & 0.3140 \\
\hline Inhaled steroids* & 0.547 & $0.426-0.703$ & 1.159 & $0.614-2.188$ & 0.649 \\
\hline \multicolumn{6}{|l|}{ Oral steroids } \\
\hline No & 1.000 & reference & & & \\
\hline $5 \mathrm{mg}$ & 2.354 & $0.937-5.914$ & 2.279 & $0.902-5.762$ & 0.082 \\
\hline $5 \mathrm{mg}^{*}$ inhaled steroids & 1.078 & $0.577-2.013$ & 1.083 & $0.564-2.083$ & 0.647 \\
\hline $10 \mathrm{mg}$ & 3.296 & $1.757-6.183$ & 2.340 & $1.235-4.435$ & 0.009 \\
\hline $10 \mathrm{mg}^{*}$ inhaled steroids & 1.636 & $0.910-2.940$ & 1.638 & $0.908-2.955$ & 0.810 \\
\hline $15 \mathrm{mg}$ & 5.989 & $3.027-11.85$ & 4.031 & $1.994-8.149$ & 0.000 \\
\hline $15 \mathrm{mg}^{*}$ inhaled steroids & 1.950 & $1.00-3.804$ & 1.616 & $0.817-3.196$ & 0.167 \\
\hline
\end{tabular}

Data presented as relative risk (RR) or 95\% confidence interval (CI). BMI: body mass index; FEV1: forced expiratory volume in one second; $P \mathrm{a}_{2} \mathrm{O}_{2}$ : arterial oxygen tension; $\mathrm{Pa}_{\mathrm{a}} \mathrm{CO}_{2}$ : arterial carbon dioxide tension ${ }^{+}: 0=$ no, $1=$ yes; ${ }^{\#}: 0=$ males $1=$ females; *: interaction with inhaled steroids $0=$ no, $1=$ yes.

Figure 1a shows the Kaplan-Meier plot for oral glucocorticoid use stratified by dose, after exclusion of patients who were using inhalation steroids either as only treatment or in combination with oral steroids. Figure 1b presents the Kaplan-Meier plot for glucocorticoid use stratified by inhalation, after exclusion of patients using oral steroids. Mortality was significantly higher in patients using $\geqslant 10 \mathrm{mg} \cdot \mathrm{day}^{-1}$ oral glucocorticoids, but no differences in survival were observed between patients on inhaled steroids only compared to nonsteroid users.

Baseline characteristics of patients stratified by oral and/or inhaled steroids into four groups are shown in table 3. Differences between the groups were small with the exception of a significantly $(\mathrm{p}<0.05)$ lower BMI in the oral glucocorticoid group compared to all other groups and a significantly $(\mathrm{p}<0.05)$ higher IVC in the inhaled glucocorticoid group compared to all other groups. Table 2 also shows the results of the Cox regression analysis adjusting for the above mentioned parameters as well as other measures known to affect mortality in COPD (adjusted RR). When given in doses equivalent to $10 \mathrm{mg}$ of prednisolone or higher, oral glucocorticoids had an independent adverse effect on survival, after adjusting for the influence of age, smoking, FEV1, BMI, sex, resting arterial $P \mathrm{a}, \mathrm{O}_{2}$ and $\mathrm{Pa}_{2} \mathrm{CO}_{2}$. When combined with inhaled corticosteroids, the adverse effect of oral corticosteroids appeared to be substantially smaller. Mean prednisolone dose in the group receiving only oral corticosteroids was significantly higher than in the group receiving both oral and inhaled corticoids (10.2 (3.6) mg versus 8.9 (3.1) mg; $\mathrm{p}<0.01)$.

\section{Discussion}

In a retrospective multivariate analysis which included moderate to severe COPD patients, a significant dose dependent relationship was found between the use of oral glucocorticoids and overall mortality, adjusted for spirometry, resting arterial blood gases, sex, BMI, age and use of inhaled steroids. Combined with inhaled corticosteroids, the relative risk of oral glucocorticoid use appeared to be significantly smaller.

It is not known why maintenance treatment with corticosteroids was prescribed in the patients, since their treatment was started long before they were admitted to the rehabilitation centre and information

Table 3. - Baseline characteristics of chronic obstructive pulmonary disease patients stratified by the use of oral and inhaled glucocorticoids

\begin{tabular}{|c|c|c|c|c|}
\hline & \multicolumn{4}{|c|}{ Glucocorticoid use } \\
\hline & None & Only inhaled & Inhaled and oral & Only oral \\
\hline Subjects $n$ & 44 & 121 & 290 & 101 \\
\hline Age yr & $65 \pm 8$ & $63 \pm 8$ & $65 \pm 9$ & $68 \pm 6$ \\
\hline $\mathrm{BMI} \mathrm{kg} \cdot \mathrm{m}^{-2}$ & $23.4 \pm 4.5$ & $23.8 \pm 4.4$ & $23.5 \pm 4.4$ & $21.8 \pm 3.6$ \\
\hline FEV 1 pre $\%$ & $37 \pm 11$ & $39 \pm 12$ & $36 \pm 13$ & $33 \pm 12$ \\
\hline FEV 1 post $\%$ & $40 \pm 10$ & $43 \pm 12$ & $39 \pm 15$ & $36 \pm 12$ \\
\hline IVC $\%$ & $68 \pm 19$ & $79 \pm 16$ & $72 \pm 18$ & $68 \pm 17$ \\
\hline $\mathrm{Pa}_{\mathrm{a}, \mathrm{O}_{2}} \mathrm{kPa}$ & $8.7 \pm 1.4$ & $9.2 \pm 1.3$ & $8.9 \pm 1.6$ & $8.3 \pm 1.4$ \\
\hline $\mathrm{Pa}_{2} \mathrm{CO}_{2} \mathrm{kPa}$ & $5.6 \pm 1.0$ & $5.3 \pm 0.8$ & $5.4 \pm 0.9$ & $5.5 \pm 1.0$ \\
\hline
\end{tabular}

Data presented as mean \pm SD. BMI: body mass index; FEV1: forced expiratory volume in one second; IVC: inspiratory vital capacity; $\mathrm{Pa}, \mathrm{O}_{2}$ : arterial oxygen tension; $\mathrm{Pa}_{\mathrm{a}} \mathrm{CO}_{2}$ : arterial carbon dioxide tension. 

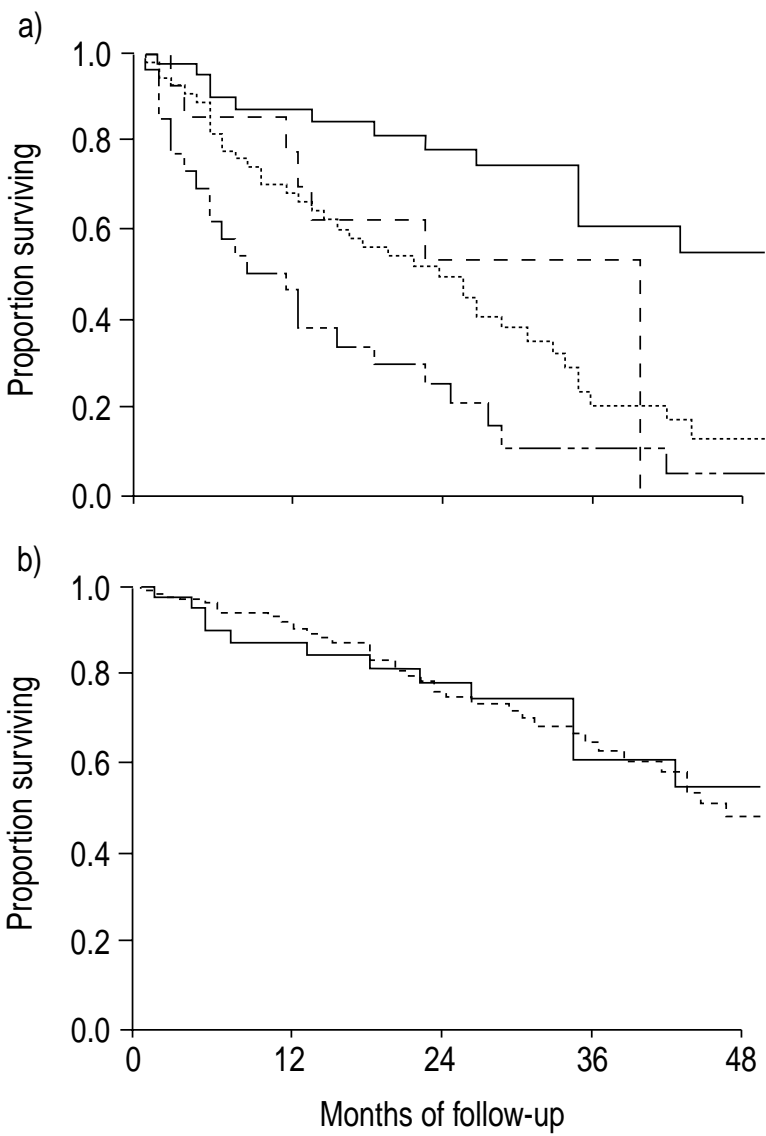

Fig. 1. - Kaplan-Meier plot: a) oral glucocorticoid use categorized by dose (5 mg: ---; $10 \mathrm{mg}: \cdots \cdots ; 15 \mathrm{mg}$ : - - - - ) compared to no maintenance glucocorticoid $(-)$ treatment; b) inhaled glucocorticoid use (- - -) compared to no maintenance glucocorticoid treatment (—). Oral GC $0 \mathrm{mg}: \mathrm{n}=43$, log rank test; $5 \mathrm{mg}: \mathrm{n}=16$, Chisquared $=3.65, \quad \mathrm{p}=0.056 ; \quad 10 \mathrm{mg}: \mathrm{n}=59$, Chi-squared $=14.75$, $\mathrm{p}=0.0001 ; 15 \mathrm{mg}: \mathrm{n}=32$, Chi-squared $=24.88, \mathrm{p}=0.000$. Inhaled GC: $n=156$, Chi-squared $=0.05$, nonsignificant.

about reason and exact time of prescription could not be reliably obtained. It is recognized that this is also an important limitation of the present study. It is important to note that these patients had been referred to the rehabilitation centre by a large number of chest physicians from various hospitals, mainly in the southeastern part of the Netherlands and upon release from the centre were sent back to their own doctor. In the statistical analysis, all known determinants of disease severity and of survival in COPD were adjusted for, except for pulmonary artery pressure, diffusing capacity for $\mathrm{CO}$ and static lung volumes which were not measured in all patients. Most variables were not significantly different between groups stratified by use of oral glucocorticoids and the FEV1 expressed as \% pred was not even significantly related to mortality on multivariate analysis. This raises the important question of which subjective characteristic, or objective criterium leads to maintenance treatment with oral corticosteroids in some patients and not in others. It is recognized that the observed effect of oral glucocorticoid treatment on mortality may reflect an indication bias, like frequent disease exacerbations. The dose dependency of the association however might argue against this assumption. On the other hand, that this could also be the other way around is also recognized. The more severe the disease, the more life-threatening exacerbations, the less the prescribing physician is concerned with reducing the maintenance treatment out of concern for side-effects. Indeed table 3 shows that lung function was most impaired in the group on oral glucocorticoids only. Furthermore, other yet unidentified reasons associated with maintenance glucocorticoid treatment in COPD like decreased muscle function, exercise capacity or health status are not excluded. In this context the present study clearly illustrates the importance of a broader characterization of patients with COPD, not only on base of the degree of local lung function impairment, but also on disability and handicap level.

Most clinicians would consider prescribing inhaled corticosteroids in patients with frequent exacerbations or in the presence of a certain degree of reversibility of airflow obstruction. According to the post bronchodilator response, all patients in the present study however were suffering from moderate to severe irreversible obstructive pulmonary disease. Nevertheless one recent study in patients with moderate to severe COPD showed a significant decrease in symptoms like dyspnoea and sputum scores as well as a significant better 6 minute walking distance after high dose inhaled corticosteroids [9]. This result is not remarkable since it is well established that FEV1 is poorly correlated with dyspnoea, exercise tolerance and health status [10]. Furthermore, the Isolde study showed significantly less exacerbations after fluticason compared to placebo independent of the change in FEV1 [11]. Theoretically this result could be translated to the observed decreased mortality in this study, based on the study by CoNNORs et al. [12] showing that acute exacerbation frequency is associated with increased mortality. Indirectly one could even speculate that inhaled steroids might partly reverse the detrimental effects of oral steroids as was indeed observed in the statistical analysis. Potential acute or systemic antiinflammatory effects of inhaled corticosteroids however, remain to be determined [13].

Proof of positive effects of systemic corticosteroids on these parameters is scanty [1]. Yet many textbooks advise use of long-term corticosteroids in severe COPD and indeed, a recent study from the Netherlands demonstrated that many elderly patients with COPD are on maintenance treatment with glucocorticoids [14]. Side effects of sustained use of systemic corticosteroids on the opposite are well documented and include suppression of the hypothalamic-adrenal axis, infectious complications, myopathy, osteoporosis, glucose intolerance, gastrointestinal effects such as peptic ulcers, psychiatric effects, skin bruising, cardiovascular effects such as hypertension and cataracts [15]. However, these effects do not necessarily lead to early death. During the last $10 \mathrm{yrs}$, several studies have pointed towards myopathy as a potentially dangerous complication of long-term systemic use of corticosteroids [16], especially as a result of the observed deleterious effects of muscle weakness on functional status of patients with COPD $[17,18]$. In addition, in a recent study it was found that peripheral muscle weakness, represented by reduced quadriceps force, was an independent contributor of health care costs and preliminary data by the 
same group even suggest an adverse influence on mortality [19]. This lends support to a possible role of steroid myopathy in the observed association between oral steroid use and increased mortality. These effects of glucocorticosteroids are not limited to limb muscle function, but may also affect respiratory muscle function, at least when used in high doses [20]. Other than myopathic changes, glucocorticoids are furthermore known to cause increased protein breakdown and muscle wasting, especially the fluoridated corticosteroids [21], but no clinical data are available comparing respiratory and peripheral muscle function between patients with COPD using different glucocorticoid types at equipotent dose. For the present analysis, unfortunately no data on muscle function were available for the whole group, but no differences in survival were found between prednisone and equipotent doses of the fluoriolated betamethasone (data not shown). Prospective studies have to be conducted to assess more specific prognostic significance of steroid induced muscle dysfunction in COPD. Infectious complications resulting from suppression of the immune system have also to be considered. Corticosteroids in sufficient doses have immunosuppressive effects and impair antibody production. In a meta-analysis, STUCK et al. [22] found a relative risk of lethal and nonlethal infectious complications of systemic corticosteroids of 1.6. The risk was higher in patients who were prescribed corticosteroids for renal and neurological diseases than in patients with a pulmonary diagnosis. Patients with diabetes were excluded from the present analysis. Therefore, complications of this side-effect of steroid use cannot be held responsible. Diabetes in itself may effect prognosis, and exclusion of diabetes in this study may therefore lead to underestimation of the deleterious effects of corticosteroids on prognosis in COPD. Osteoporosis occurs in many patients using long-term systemic corticosteroids and even inhaled steroids have been shown to affect bone metabolism [23]. In a recent study performed at the same pulmonary rehabilitation centre (not including any patients of this study), an increased prevalence of bone mineral loss in COPD patients compared to healthy control subjects was found, irrespective of the use of maintenance glucocorticoids [24]. In itself osteoporosis is not a lethal complication, but indirectly, immobility or fractures resulting from osteoporosis can have effects on survival.

In conclusion despite the limitations in the study design, this study is another example to point out that when starting maintenance treatment with glucocorticoids, clinicians should carefully consider if the expected benefits from treatment outweigh the potential harm, in terms of side-effects and even in terms of increased mortality.

\section{References}

1. Callahan CM, Dittus RS, Katz BP. Oral corticosteroid therapy for patients with stable chronic obstructive pulmonary disease. A meta-analysis. Ann Intern Med 1991; 114: 216-223.

2. Banner AS. Emerging role of corticosteroids in chronic obstructive pulmonary disease. Lancet 1999; 354: $440-441$.
3. Ziment I. Pharmacologic therapy of obstructive airway disease. Clin Chest Med 1990; 11: 461-486.

4. Postma DS, Peters I, Steenhuis EJ, Sluiter HJ. Moderately severe chronic airflow obstruction. Can corticosteroids slow down obstruction? Eur Respir $J$ 1988; $1: 22-26$

5. Thompson WH, Nielson CP, Carvalho P, Charan NB, Crawley JJ. Controlled trial of oral prednisone in outpatients with acute COPD exacerbation. Am J Respir Crit Care Med 1996; 154: 407-412.

6. Niewoehner DE, Erbland ML, Deupree RH, et al. Effect of systemic glucocorticoids on exacerbations of chronic obstructive pulmonary disease. Department of Veterans Affairs Cooperative Study Group. N Engl J Med 1999; 340: 1941 - 1947.

7. McEvoy CE, Niewoehner DE. Adverse effects of corticosteroid therapy for COPD. A critical review. Chest 1997; 111: 732-743.

8. Quanjer $\mathrm{PH}$, editor. Standardized lung function testing. Bull Eur Physiopathol Respir 1983; 19: 7-44.

9. Paggiaro PL, Dahle R, Bakran I, Frith L, Hollingworth K, Efthimiou J. Multicenter randomized placebo-controlled trial of inhaled fluticasone propionate in patients with chronic obstructive pulmonary disease. Lancet 1998; 351: $773-780$.

10. Curtis JR, Deyo RA, Hudson LD. Pulmonary rehabilitation in chronic respiratory insufficiency. 7. Health-related quality of life among patients with chronic obstructive pulmonary disease. Thorax 1994; 49: $162-170$.

11. Burge PS, Calverley PM, Jones PW, Spencer S, Anderson JA, Maslen TK. Randomised, double blind, placebo controlled study of fluticasone propionate in patients with moderate to severe chronic obstructive pulmonary disease: the ISOLDE trial. BMJ 2000; 320: 1297-1303.

12. Connors F, Dawson NV, Thomas C, et al. Outcomes following acute exacerbations of severe chronic obstructive lung disease. Am J Respir Crit Care Med 1996; 154: 959-967.

13. Keatings VM, Jatakanon A, Worsdell YM, Barnes PJ. Effects of inhaled and oral glucocorticoids on inflammatory indices in asthma and COPD. Am J Respir Crit Care Med 1997; 155: 542-548.

14. Offerhaus MP, Haan IB, Herijgers DC, Cools HJ. Use of drugs for CNSLD (asthma and COPD) in Dutch residential homes and nursing homes. Tijdschr Gerontol Geriatr 1997; 28: $101-105$.

15. Robertson A, Gove R, Wieland G, Burge P. A doubleblind comparison of oral prednisolone $40 \mathrm{mg} /$ day with inhaled beclomethasone dipropionate 1500 microg/ day in patients with adult onset chronic obstructive airways disease. Eur J Respir Dis 1986; 146: 565-569.

16. Decramer M, de Bock V, Dom R. Functional and histologic picture of steroid-induced myopathy in chronic obstructive pulmonary disease. Am J Respir Crit Care Med 1996; 153: 1958 - 1964.

17. Bernard S, LeBlanc P, Whittom F, et al. Peripheral muscle weakness in patients with chronic obstructive pulmonary disease. Am J Respir Crit Care Med 1998; 158: $629-634$.

18. Gosselink R, Troosters T, Decramer M. Peripheral muscle weakness contributes to exercise limitation in COPD. Am J Respir Crit Care Med 1996; 153: 976 980.

19. Decramer M, Gosselink R, Troosters T, Schepers R. Peripheral muscle weakness is associated with reduced 
survival in COPD. Am J Respir Crit Care Med 1998; 157: A19.

20. Picado C, Fiz JA, Montserrat JM, et al. Respiratory and skeletal muscle function in steroid-dependent bronchial asthma. Am Rev Respir Dis 1990; 141: $14-20$.

21. Koerts De Lang E, Schols AM, Wouters EF, GayanRamirez G, Decramer M. Contractile properties and histochemical characteristics of the rat diaphragm after prolonged triamcinolone treatment and nutritional deprivation. J Muscle Res Cell Motil 1998; 19: 549-555.
22. Stuck AE, Minder CE, Frey FJ. Risk of infectious complications in patients taking glucocorticosteroids. Rev Infect Dis 1989; 11: 954-963.

23. Pouw EM, Prummel MF, Oosting H, Roos H, Endert E. Beclomethasone inhalation decreases serum osteocalcin concentrations. BMJ 1991; 302: $627-628$.

24. Engelen MP, Schols AM, Heidendal GA, Wouters EF. Dual-energy X-ray absorptiometry in the clinical evaluation of body composition and bone mineral density in patients with chronic obstructive pulmonary disease. Am J Clin Nutr 1998; 68: 1298 - 1303. 